\title{
Mechanical properties of myxomatous mitral valves
}

\author{
J. Edward Barber, BS \\ F. Kurtis Kaspera \\ Norman B. Ratliff, MD \\ Delos M. Cosgrove, MD \\ Brian P. Griffin, MD ${ }^{\mathrm{d}}$ \\ Ivan Vesely, PhDa
}

From the Department of Biomedical
Engineering, The Lerner Research Institute,
The Cleveland Clinic Foundation, ${ }^{\mathrm{a}}$ and the
Departments of Anatomic Pathology,
Thoracic and Cardiovascular Surgery, ${ }^{\mathrm{c}}$ and
Cardiology, ${ }^{\mathrm{d}}$ The Cleveland Clinic Founda-
tion, Cleveland, Ohio.
This work was supported in part by research
grants from the northeast Ohio and national
branches of The American Heart Association
and by The Mareb Foundation, Inc, Basking
Ridge, NJ.

Received for publication June 21, 2000; revisions requested Feb 8, 2001; revisions received May 18, 2001; accepted for publication May 23, 2001.

Address for reprints: Ivan Vesely, $\mathrm{PhD}$, Department of Biomedical Engineering/ ND20, The Cleveland Clinic Foundation, 9500 Euclid Ave, Cleveland, OH 44195 (Email: vesely@bme.ri.ccf.org).

J Thorac Cardiovasc Surg 2001;122:955-62

Copyright (c) 2001 by The American Association for Thoracic Surgery

$0022-5223 / 2001 \$ 35.00+0 \quad \mathbf{1 2 / 1 / 1 1 7 6 2 1}$

doi: $10.1067 / \mathrm{mtc} .2001 .117621$
Objective: We sought to characterize the mechanical properties of normal and myxomatous mitral valve tissues.

Methods: We tested 113 mitral valve sections from patients undergoing mitral valve repair or replacement for myxomatous mitral valve prolapse and sections from 33 normal valves obtained at autopsy.

Results: Myxomatous mitral valve leaflets were more extensible than normal leaflets when tested parallel to the free edge $(41.2 \% \pm 18.5 \%$ vs $17.3 \% \pm 6.7 \%$ circumferential strain [mean $\pm \mathrm{SD}$ ]; $P<.001$ ), as well as perpendicular to the free edge $(43.2 \% \pm 19.4 \%$ vs $17.3 \% \pm 6.7 \%$ radial strain $P<.001)$. Myxoid leaflets were less stiff circumferentially $(4.0 \pm 1.6$ vs $6.1 \pm 1.4 \mathrm{kN} / \mathrm{m} ; P<.001)$ and radially $(4.5 \pm$ 1.1 vs $6.1 \pm 1.4 \mathrm{kN} / \mathrm{m} ; P<.001)$ than normal leaflets. Leaflet strength, however, was similar in both groups.

Conclusions: Myxomatous mitral valve leaflets are physically and mechanically different from normal mitral valve leaflets. They are more extensible and less stiff. Compared with chordae examined previously, however, they are affected much less. Myxomatous mitral valve disease may therefore affect the collagen in the chordae more severely than that in the leaflets.

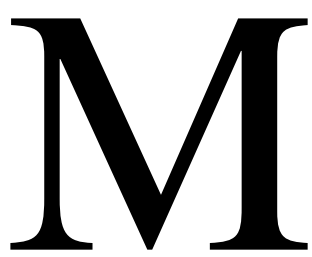

yxomatous changes in mitral valve tissue are the leading cause of leaflet prolapse and mitral regurgitation in the United States. ${ }^{1}$ Although leaflet prolapse is a common diagnosis, not all patients have severe mitral regurgitation and require an operation. For patients who require surgical intervention, the optimal approach is valve repair. ${ }^{2}$ This involves removal of the redundant portion of the prolapsed leaflet and support of the repaired valve with an annuloplasty ring. ${ }^{3}$ Valve repair has been highly successful and has been shown to preserve left ventricular function more than valve replacement. ${ }^{3,4} \mathrm{An}$ ongoing concern in its use, however, is the long-term durability of the repair, given that the valve tissue itself is diseased and likely mechanically compromised.

Although the clinical, echocardiographic, and pathologic abnormalities in myxomatous valve disease have been described, ${ }^{5}$ the biomechanical changes that occur in the myxoid leaflets have not been well characterized. Previous work has focused mainly on the mechanics of normal mitral valve tissue. ${ }^{6-15}$ Kunzelman and Cochran ${ }^{11-15}$ have studied the mechanics of the mitral apparatus extensively and surveyed the differences between anterior and posterior leaflets and between basal and marginal chordae. However, they did not test human tissues or the effects of myxoid degeneration. We have previously reported on the physical and mechanical properties of myxomatous mitral valve chordae and have found them to be very different from those of normal chordae. ${ }^{16}$ 

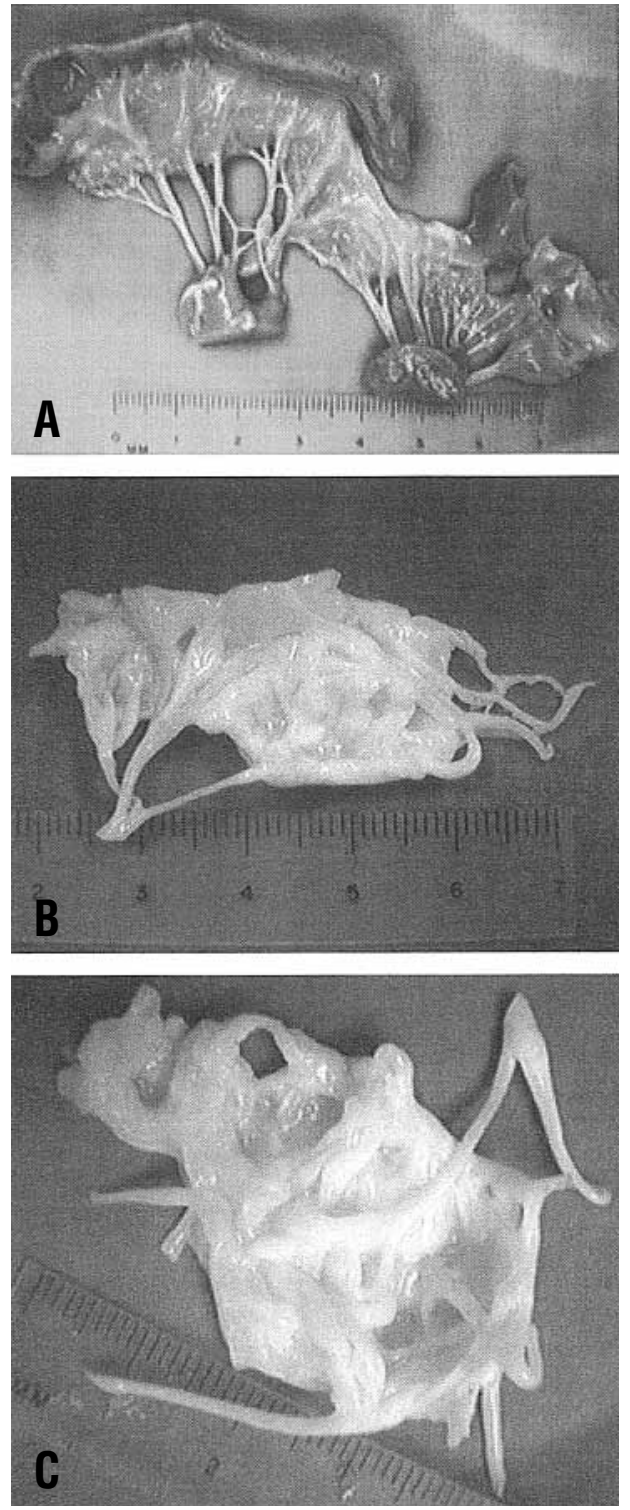

Figure 1. Normal mitral valve (A) and myxomatous mitral valve tissue (B and C). Note the extended chordae, the hooding of the free edge of the valve, and the increased thickness of the chordae in the myxoid tissue compared with that in the normal valve. Myxomatous mitral valve resections such as these are usually taken from the posterior leaflet.

Because mitral valve prolapse is diagnosed primarily from the appearance and function of the leaflets, a separate study on myxoid leaflet tissues was conducted. We were specifically interested in determining whether leaflets from myxomatous mitral valves had mechanical properties significantly different from those of normal valves and whether these differences could help explain the mechanism of leaflet prolapse.
TABLE 1. Distribution of test samples (and valves) used in the biomechanical study of myxoid and normal mitral valves

\begin{tabular}{llc}
\hline & \multicolumn{2}{c}{ Leaflets, No. of samples from (n) valves } \\
\hline Myxoid & Anterior circumferential & $5(4)$ \\
& Posterior circumferential & $82(77)$ \\
& Anterior radial & $5(4)$ \\
\multirow{3}{*}{ Normal } & Posterior radial & $84(74)$ \\
& Anterior circumferential & $17(14)$ \\
& Posterior circumferential & $8(7)$ \\
& Anterior radial & $16(11)$ \\
& Posterior radial & $2(2)$
\end{tabular}

Note that most specimens in the myxoid group were from the posterior leaflet.

\section{Methods}

\section{Tissue Procurement}

Whole normal mitral valves, with no visible evidence of disease, were obtained at autopsy from individuals who had died of noncardiac causes. These valves were harvested less than 24 hours after death, placed in physiologic saline (Hanks solution with $0.002 \%$ germicide-algicide), and taken to the laboratory. Valves from subjects between 16 and 70 years of age were included in the normal group.

Portions of myxomatous mitral valve leaflets (Figure 1) were obtained from patients undergoing either mitral valve repair or replacement for severe mitral regurgitation $(\geq 3+$ on color Doppler echocardiography) for primary myxomatous mitral valve prolapse. At the time of the operation, all excised valvular tissue was placed in saline solution in a sealed plastic container and sent to the surgical pathology department for routine gross examination. Such samples were collected each day by the investigators, examined grossly to confirm myxomatous features, placed in saline solution, and stored at $4{ }^{\circ} \mathrm{C}$ for up to 5 days before testing.

Specimens were prepared by first trimming away all chordae and then cutting the leaflets into rectangular strips oriented in either the circumferential or radial direction. The circumferential direction was defined as parallel to the free edge, and the radial direction was defined as from the free edge to the basal attachment to the anulus (Figure 2). All leaflet test strips were $10 \mathrm{~mm}$ wide and at least $14 \mathrm{~mm}$ long, and radial and circumferential strips were analyzed separately because of expected anisotropy of the tissue. ${ }^{13}$

A total of 113 myxomatous and 33 normal mitral valve specimens were obtained. From the myxoid valves, we obtained $87 \mathrm{cir}-$ cumferential and 89 radial leaflet strips (Table 1). From the normal valves, we obtained 25 circumferential and 18 radial leaflet strips. In the myxoid population there were 85 male and 28 female subjects. In the normal population there were 18 male and 12 female subjects and 3 subjects whose sex was unknown. Inclusion into the myxoid group was based on pathologic examination (thickened central layer ${ }^{17}$ ) and echocardiographic findings (thickened, redundant leaflets and dilated anulus ${ }^{18}$ ). Tissues from patients with Marfan syndrome and ischemic heart disease were excluded. The average patient age was $57 \pm 12$ years in the myxoid group and 37 \pm 14 years in the normal group. 


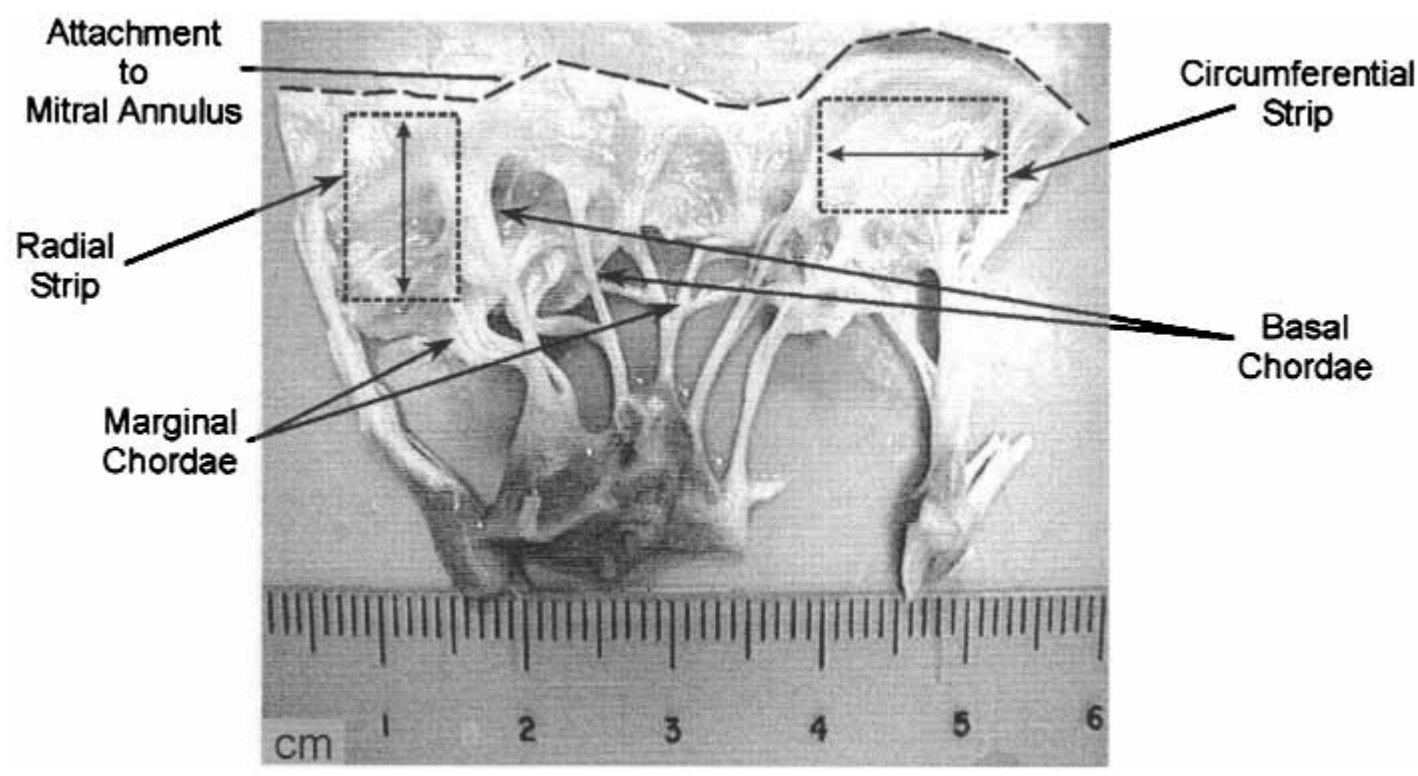

Figure 2. Normal mitral valve depicting the orientation of circumferential and radial samples, as well as basal and marginal chordae. Note that although radial and circumferential specimens were taken from different locations from each valve, their orientation with respect to the valve was maintained.

\section{Tensile Testing}

Tissue specimens were gripped at both ends with 2-piece Delrin clamps lined with sandpaper and secured in an Instron servohydraulic testing machine (model 8511; Instron, Canton, Mass). Specimens were immersed in a bath of Hanks solution heated to $37^{\circ} \mathrm{C}$ during all mechanical tests. The grips were first moved 1 to $2 \mathrm{~mm}$ closer together to slightly wrinkle the tissue and to ensure no preload. The tissue was then preconditioned by continuously loading and unloading at $4 \mathrm{~mm} / \mathrm{s}$ to a predetermined load (between 200 and $400 \mathrm{~g}$ ) until the load-displacement curve was repeatable. The last load-elongation cycle was recorded for analysis. The stiffness and extensibility of the tissue were calculated from this load-elongation curve (Figure 3). To measure stress relaxation, the tissue was stretched at $4 \mathrm{~mm} / \mathrm{s}$ to the preconditioning load and held for 100 seconds while the decay of the load over time was recorded. A curve of load versus log time was plotted, and the stress-relaxation slope was calculated. Finally, the tissue was loaded at $4 \mathrm{~mm} / \mathrm{s}$ until it failed, and the failure strength and failure strain were recorded (Figure 3). Other parameters (eg, volume, weight, and crosssectional area) were measured for each of the specimens after mechanical testing was completed.

\section{Data Analysis}

All data were examined by means of customized software programs written in Mathematica (Wolfram Research, Champaign, Ill). Comparisons of mechanical properties between normal and myxoid tissues were performed by means of a $t$ test or MannWhitney rank sum test.

In the ideal case, comparisons between the myxoid and normal tissues should be done between like specimens (ie, myxoid anterior leaflets cut in the radial direction vs normal anterior leaflets cut in the radial direction). Unfortunately, such perfectly matched speci-

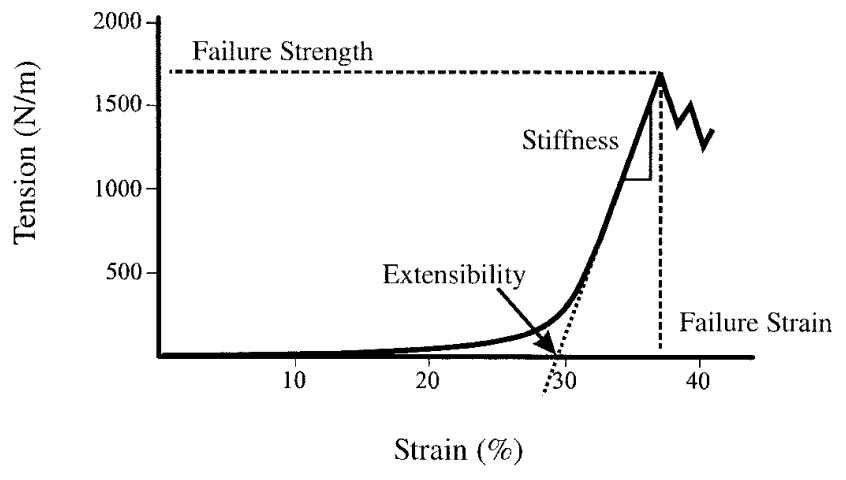

Figure 3. Typical load-elongation curve showing how mechanical properties are calculated. First, load in grams is converted into tension (newtons per meter) by expressing load as force (newtons) and normalizing for specimen width. Elongation is converted to strain by normalizing for specimen length. From the resulting tension-versus-strain curve, stiffness is computed as the slope of the linear range, and extensibility is obtained from the intersection of the stiffness tangent with the strain axis. Failure strength and strain are measured at the peak of the curve.

mens were not always available. Repair of the regurgitant myxoid mitral valve usually involves the removal of a portion of the posterior leaflet. The anterior leaflet is usually left intact. Thus, most myxoid tissues available for study were mainly from the posterior leaflet (Table 1). Comparisons between myxoid and normal tissues were therefore reported only for those data obtained from the posterior leaflet. The normal posterior leaflet, however, is extremely small, making it difficult to cut $10 \mathrm{~mm}$-wide strips of tissue from 


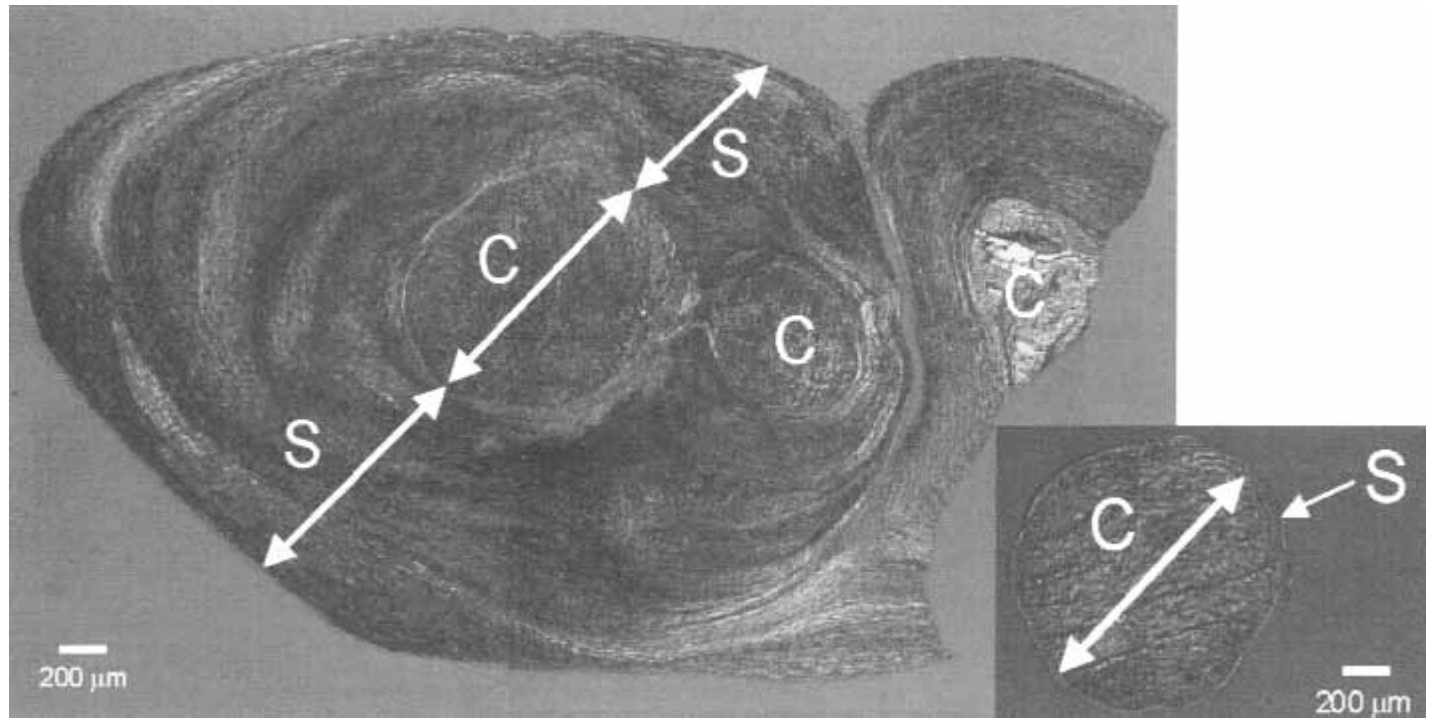

Figure 4. Representative histologic sections of picrosirius red-stained myxoid chordae viewed under polarized light microscopy. Note the fibrous tissue that appears to surround the original chords. Inset is a typical image of a normal chorda. $C$, Collagen core; $S$, fibrous sheath.

TABLE 2. Comparison of circumferential and radial leaflet test strips taken from the posterior leaflet of myxoid and normal mitral valves

\begin{tabular}{lccc}
\hline & Circumferential & Radial & Pvalue \\
\hline Myxoid & & & \\
Extensibility (\% strain) & $37.2(27.8-51.2)^{*}$ & $39.7(29.0-52.5)$ & .405 \\
Stiffness (kN/m) & $3.9(2.7-5.0)^{*}$ & $4.6(3.8-5.2)$ & .008 \\
Failure strain (\% strain) & $52.2 \pm 16.1$ & $62.0 \pm 16.6$ & .001 \\
Failure strength (N/m) & $844(630-1149)^{*}$ & $733(597-975)$ & .077 \\
Relaxation slope & $10.9 \pm 5.0$ & $12.3 \pm 3.9$ & .120 \\
$\quad(\%$ tension/log[s]) & & & \\
Normal & & & \\
Extensibility (\% strain) & $15.5 \pm 6.2$ & $24.1 \pm 4.0$ & .105 \\
Stiffness (kN/m) & $6.1 \pm 1.6$ & $6.4 \pm 0.3$ & .777 \\
Failure strain (\% strain) & $34.9 \pm 8.5$ & $35.6 \pm 0.4$ & .915 \\
Failure strength (N/m) & $981 \pm 373$ & $657 \pm 73.4$ & .274 \\
Relaxation slope & $11.3 \pm 2.8$ & $9.2 \pm 0.2$ & .353 \\
$\quad$ (\% tension/log[s]) & & & \\
\hline
\end{tabular}

Note that no significant differences were found between normal circumferential and normal radial test strips. All values are means \pm SD.

* Median (25th-75th percentile) in instances where a rank sum test was performed.

the leaflet with the long axis oriented in the radial direction (from the anulus to the free edge). Most of the leaflet strips obtained from the normal posterior leaflets were therefore oriented circumferentially (along the margin of the posterior leaflet). Comparison of mechanical properties between radial and circumferential strips from the normal posterior leaflet revealed no significant differences between the two (Table 2). This allowed us to group the normal radial and normal circumferential test strips, thus increasing the sample size of the normal posterior leaflet strips. The grouped radial and circumferential test strips from the normal posterior leaflet were then compared with radial myxoid posterior leaflets and with circumferential myxoid posterior leaflets.

\section{Results}

Myxoid posterior leaflet test strips were thicker $(P<.001)$ and heavier $(P<.001)$ than the test strips of tissue taken from normal posterior leaflets (Table 3). Myxoid posterior leaflets were significantly more extensible $(P<.001)$ and less stiff $(P<.001)$, both circumferentially and radially, than the normal posterior leaflets (Table 3 ). Although the myxoid posterior circumferential and radial strips had the same failure strength as the normal leaflets, their failure strain was $58 \%$ greater $(P=.005)$ than that of the normal leaflets (Table 3).

There were no differences in the stress-relaxation data of the myxoid and normal groups. Histologic observations of representative specimens showed results consistent with those of previous reports. What is pertinent to the analysis of the mechanical properties is the observation of considerable fibrosis or sheath-like covering around the myxoid chordae, particularly near their insertion into the leaflets (Figure 4).

\section{Discussion}

Mechanical analyses of diseased mitral valve tissues have been relatively sparse. The work of Clark ${ }^{6}$ and of Ghista and $\mathrm{Rao}^{7,8}$ in the early 1970 s, as well as more recent studies by Kunzelman and Cochran, ${ }^{13}$ have focused on normal mitral valve leaflets and chordae. Our results for normal human 


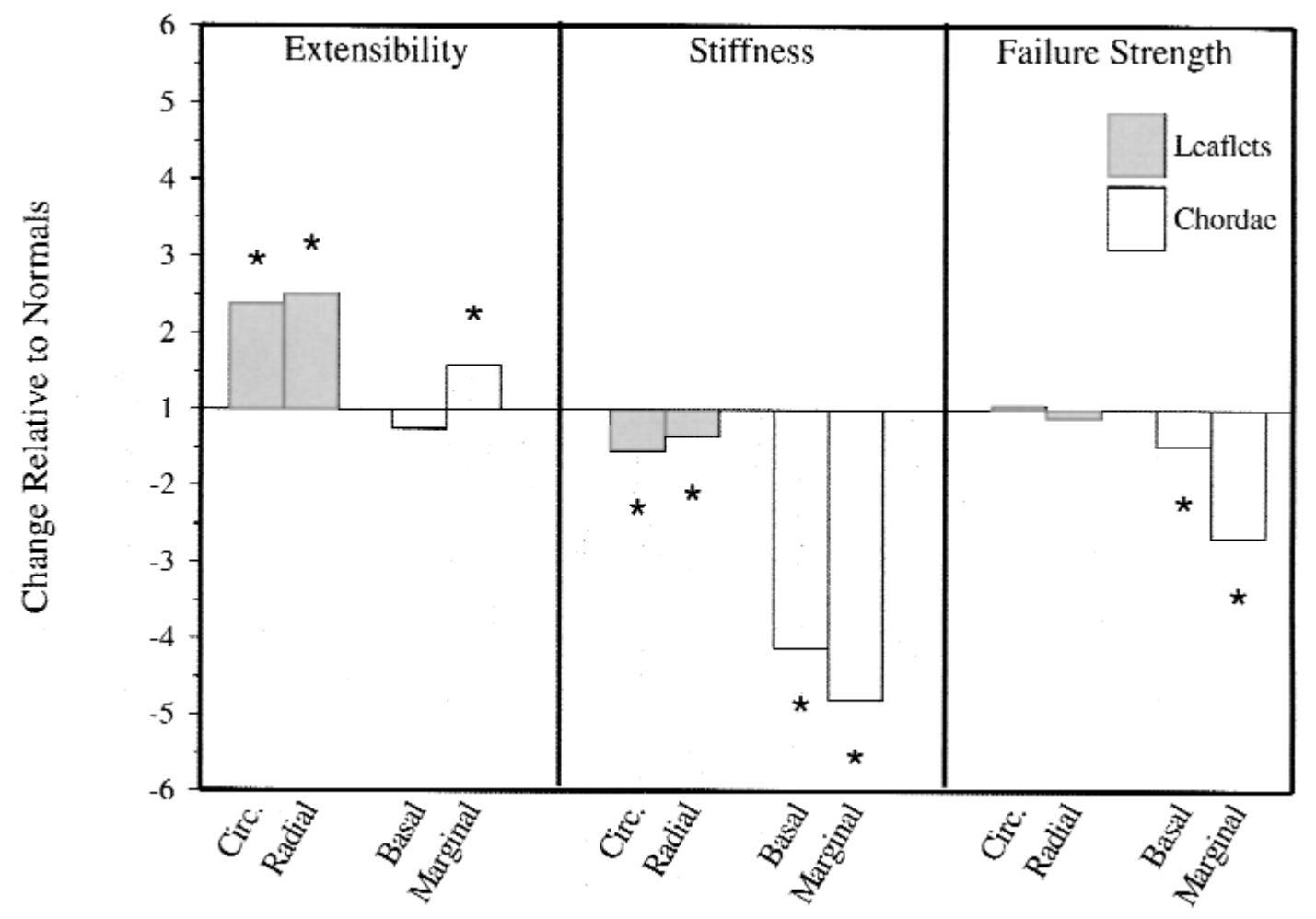

Figure 5. Comparison of the relative changes that myxoid disease produces in the mechanics of leaflets and chordae. The chordal data were adapted from our previous article ${ }^{16}$ and are included here for comparison with that from the leaflets. Note that the failure strength of myxoid basal and marginal chordae were reduced by factors of 1.5 and 2.7, respectively, whereas the changes in leaflet strength were not significant. Factor changes were calculated by dividing the larger mean (either myxoid or normal) by the smaller mean. Statistical significance between normal and myxoid data is denoted by asterisks. The largest $\boldsymbol{P}$ value in any of these groups is .03 . Circ, Circumferential.

TABLE 3. Comparison of the mechanical properties of normal leaflets (circumferential and radial test strips grouped) with myxoid circumferential and myxoid radial test strips

\begin{tabular}{lccccc}
\hline & Normal (circ and rad) & Myxoid (circ) & Myxoid (rad) & Circ $\boldsymbol{P}$ value & Rad $\boldsymbol{P}$ value \\
\hline Weight $(\mathrm{mg})$ & $146 \pm 86.5$ & $337 \pm 147$ & $361 \pm 135$ & .001 & .001 \\
Cross-sectional area $\left(\mathrm{mm}^{2}\right.$ ) & $10.5 \pm 3.4$ & $24.4 \pm 8.4$ & $26.7 \pm 8.8$ & .001 & .001 \\
Volume (cm ${ }^{3}$ & $0.151 \pm 0.09$ & $0.257 \pm 0.09$ & $0.289 \pm 0.09$ & .006 & .001 \\
Extensibility (\% strain) & $17.3 \pm 6.7$ & $41.2 \pm 18.5$ & $43.2 \pm 19.4$ & .001 & .001 \\
Stiffness (kN/m) & $6.1 \pm 1.4$ & $4.0 \pm 1.6$ & $4.5 \pm 1.1$ & .001 & .001 \\
Failure strain (\% strain) & $35.0 \pm 7.5$ & $55.4 \pm 22.0$ & $62.0 \pm 16.6$ & .005 & .001 \\
Failure strength (N/m) & $801(665-1091)^{*}$ & $844(630-1149)$ & $733(597-975)$ & .972 & .472 \\
Relaxation slope (\% tension/log[s]) & $10.8 \pm 2.6$ & $10.9 \pm 5.0$ & $12.3 \pm 3.9$ & .966 & .288
\end{tabular}

Note that myxoid leaflet test strips have the same failure strength as normal leaflet test strips. All values are means \pm SD. circ, Circumferential; rad, radial. *Median (25th-75th percentile) in the instances where a rank sum test was performed.

mitral valves are similar to those of Kunzelman and Cochran, who tested porcine mitral valves. However, because of differences in testing methods, more specific comparisons are difficult to make. In reviewing the literature we did not find a single published article describing the mechanics of myxomatous mitral valves other than our previous report on myxomatous mitral valve chordae. ${ }^{16}$ The only similar publication is from $1983,{ }^{19}$ reporting on the mechanics of myxoid tricuspid chordae. In one of the few quantitative ultrastructural studies in print, Whittaker and colleagues ${ }^{20}$ have shown that collagen from myxoid mitral valve chordae has a lower intrinsic birefringence than normal collagen, indicative of a less highly organized material at the molecular level. Accordingly, we found gross 


\section{Force}

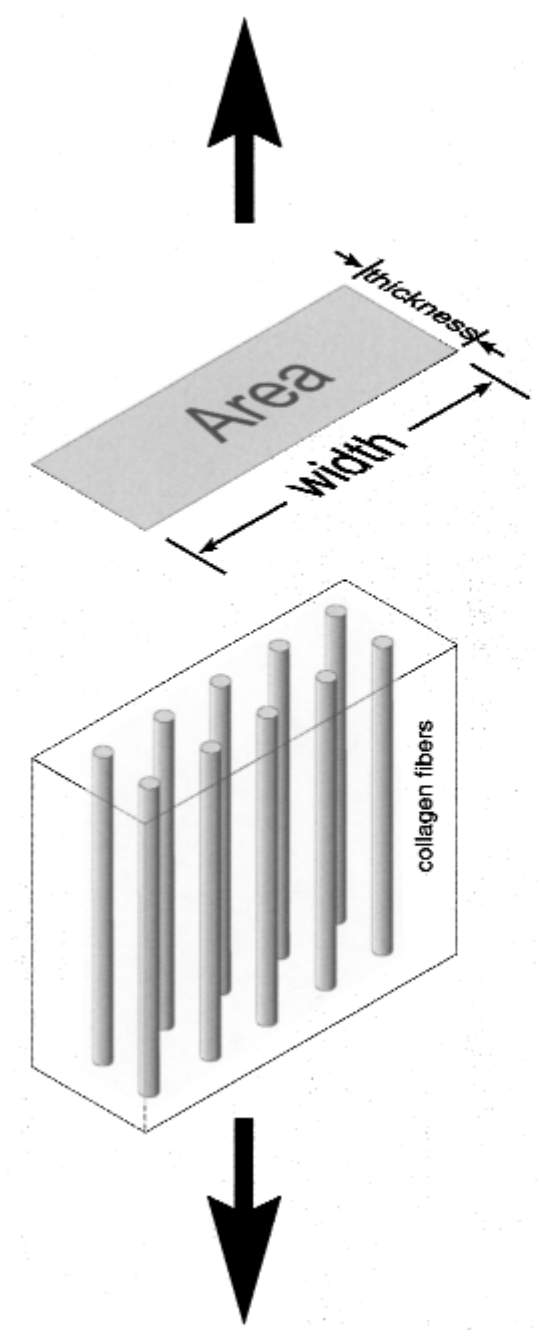

\section{Force}

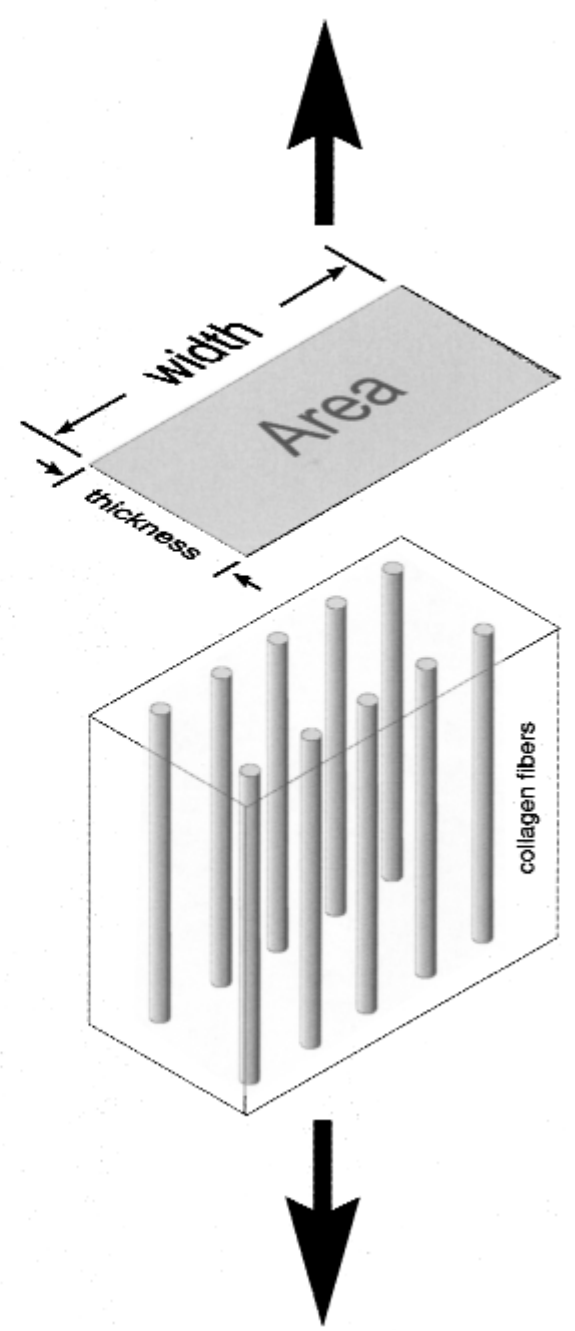

Figure 6. Diagram demonstrating how an increase in thickness may produce an increased cross-sectional area without altering the number of load-bearing collagen fibers within the leaflet segment. If the thickness is not accounted for in the analysis, the swelling will be perceived as a decrease in failure stress, even though the strength (in grams or newtons) of the leaflet is unaffected.

mechanical changes in myxoid tissues that are likely responsible for leaflet prolapse.

We conclude that myxoid mitral valve leaflets are more than twice as extensible and less stiff than normal leaflets (Figure 5). Similarly, integrating data from this study on leaflets and our previous work on chordae, ${ }^{16}$ myxoid chordae are more extensible, less stiff, and not as strong as normal chordae. The failure strength, in particular, is compromised much more in the chordae than it is in the leaflets (Figure 5). For example, in absolute terms the average failure loads of the myxoid marginal chordae were $62 \%$ lower $(0.5 \mathrm{vs} 1.3 \mathrm{~kg})$ than those of normal chordae. ${ }^{16}$
It is only after accounting for the differences in tissue dimensions that the profound changes in tissue mechanics produced by the myxomatous process become fully apparent. Stiffness and failure strength are usually expressed in terms of stress, with the units being force per cross-sectional area of the specimen tested. Force is expressed in newtons, and cross-sectional area is expressed in square meters (Figure 6). These values are often presented in pascals, where $1 \mathrm{~Pa}$ is equal to $1 \mathrm{~N} / \mathrm{m}^{2}$. Because we anticipated that the bulk of the increase in the thickness of the myxoid leaflet was caused by an accumulation of glycosaminoglycans (and hence water), we chose to present the mechanics 
of the leaflets in terms of membrane tension or force per unit width of the test strip (ie, newtons per meter). This method ignores thickness and avoids the effect of the swelling that adds bulk to the tissue without contributing any strength to the leaflet. The use of tension rather than stress as a measure of leaflet stiffness or of strength better reveals the effects of myxomatous disease on the mechanics of the collagen and elastin components. If one were to express the data in terms of stress, the increased water content would produce a misleading decrease in stiffness and failure strength. Accordingly, we found that the failure strength of the myxoid leaflets decreased very little, despite the more than 2 -fold increase in cross-sectional area. This finding implies that the number of load-bearing fibers per unit width, or their strength, has changed very little.

In comparing the relative differences between the changes that myxoid disease induces in leaflets versus in chordae, it should be noted that some of the differences observed in the chordae are geometry dependent. The 4-fold difference in failure strength between normal and myxoid chordae is largely due to the 2- to 3-fold increase in their cross-sectional area. Unlike the apparent swelling of myxoid leaflets caused by increased glycosaminoglycan content, the myxoid chordae increased their cross-sectional area through an accumulation of fibrous tissue around the original chords (Figure 4). Had this new fibrous overgrowth been composed of well-organized collagen, like the native chordae, then its relative strength (in newtons per square meters) would have remained the same, and in absolute terms (in newtons or kilograms), it would have increased. The fact that the strength was reduced 4-fold indicates that this new material played little or no role in reinforcing the chordae or providing additional strength. Indeed, in absolute terms the failure strength of the chordae dropped, despite the additional material. Not only did the new material not reinforce the chordae, but the native collagen in the interior lost some of its original strength. It is also interesting to note that disruption to the collagen, as reported in the literature, ${ }^{21}$ does not seem to affect the strength of the leaflets much but profoundly affects the strength of the chordae. Indeed, this was alluded to in the report by Whittaker and colleagues ${ }^{20}$ of decreased birefringence in myxoid chordae. We therefore believe that myxomatous mitral valve disease, in terms of its effect on collagen, should be considered more of a disease of the chordae, rather than of the leaflets.

One factor that needs to be considered in the comparison is age. Because the patients in the myxoid group were roughly 20 years older than those in the normal group, it could be argued that the compromised mechanical properties of myxoid valves resulted from the age difference. It has been shown, however, that collagen in the elderly has less crimp than collagen in the middle aged. ${ }^{10} \mathrm{~A}$ reduction in crimp would decrease the extensibility (elasticity) of the tis- sue and increase the stiffness. We found the opposite in the myxoid tissues from older patients. Our findings indicate that the compromised mechanics of myxoid valves are real and not just the result of age-related degeneration. Studies comparing properly age-matched groups may therefore demonstrate even greater differences in extensibility.

Another factor that should be taken into account is the nonuniform distribution of myxomatous changes in the valve tissues. The leaflet segments removed at the time of operation are usually those that are the most severely affected. Although this type of sampling may exaggerate the apparent severity of myxoid changes in the mitral apparatus as a whole, it is the presence of these localized myxoid changes that causes the severe clinical symptoms that require surgical intervention.

Mitral valve prolapse is a common diagnosis on echocardiography, but only a fraction of patients have mitral regurgitation. It therefore remains unclear whether the myxomatous changes observed in the mitral leaflets and chordae cause prolapse and regurgitation or are a consequence of the regurgitation. It is possible that some of the myxoid changes result from regurgitation, similar to the cusp-edge fibrosis that occurs in regurgitant aortic valves. ${ }^{17}$ Alteration in one component, through disease, may produce changes in the other component. However, the clearly abnormal chordal insertions into myxoid leaflets and the recent genetic evidence ${ }^{22}$ suggest that myxoid changes cannot be entirely acquired; genetic determinants are at least partly responsible.

In conclusion, this study has shown that myxoid leaflets are more extensible and less stiff than normal leaflets. Comparison of these data with those obtained for chordae ${ }^{16}$ suggest that myxomatous mitral valve disease affects the load-bearing capacity of the chordae more than it does the leaflets. Myxomatous mitral valve tissue is therefore clearly abnormal and may not function properly, even after successful mitral valve repair.

We thank K. Jane Grande-Allen, $\mathrm{PhD}$, for her efforts in reviewing this article.

\section{References}

1. Devereux RB. Recent developments in the diagnosis and management of mitral valve prolapse. Curr Opin Cardiol. 1995;10:107-16.

2. Akins CW, Hilgenberg AD, Buckley MJ, Vlahakes GJ, Torchiana DF, Daggett WM, et al. Mitral valve reconstruction versus replacement for degenerative or ischemic mitral regurgitation. Ann Thorac Surg. 1994;58:668-75

3. Odell JA, Orszulak TA. Surgical repair and reconstruction of valvular lesions. Curr Opin Cardiol. 1995;10:135-43.

4. Gillinov AM, Cosgrove DM, Blackstone EH, Diaz R, Arnold JH, Lytle BW, et al. Durability of mitral valve repair for degenerative disease. $J$ Thorac Cardiovasc Surg. 1998;116:734-43.

5. Kern WH, Tucker BL. Myxoid changes in cardiac valves: pathologic, clinical, and ultrastructural studies. Am Heart J. 1972;84:294-301.

6. Clark RE. Stress-strain characteristics of fresh and frozen human aor- 
tic and mitral leaflets and chordae tendineae: implications for clinical use. J Thorac Cardiovasc Surg. 1973;66:202-8.

7. Ghista DN, Rao AP. Structural mechanics of the mitral valve: stresses sustained by the valve; non-traumatic determination of the stiffness of the in vivo valve. J Biomech. 1972;5:295-307.

8. Ghista DN, Rao AP. Mitral valve mechanics-stress-strain characteristics of excised leaflets, analysis of its functional mechanics and its medical application. Med Biol Eng. 1973;11:691-702.

9. Lim KO, Boughner DR. Mechanical properties of human mitral valve chordae tendineae: variation with size and strain rate. Can J Physiol Pharmacol. 1975;53:330-9.

10. Lim KO, Boughner DR. Morphology and relationship to extensibility curves of human mitral valve chordae tendineae. Circ Res. 1976;39: 580-5.

11. Kunzelman KS, Cochran RP. Mechanical properties of basal and marginal mitral valve chordae tendineae. ASAIO Trans. 1990;36:M405-8.

12. Cochran RP, Kunzelman KS. Comparison of viscoelastic properties of suture versus porcine mitral valve chordae tendineae. J Card Surg. 1991;6:508-13.

13. Kunzelman KS, Cochran RP. Stress/strain characteristics of porcine mitral valve tissue: parallel versus perpendicular collagen orientation. J Card Surg. 1992;7:71-8.

14. Kunzelman KS, Cochran RP, Murphree SS, Ring WS, Verrier ED, Eberhart RC. Differential collagen distribution in the mitral valve and its influence on biomechanical behaviour. J Heart Valve Dis. 1993; 2:236-44.

15. Kunzelman KS, Cochran RP, Chuong C, Ring WS, Verrier ED, Eberhart RD. Finite element analysis of the mitral valve. J Heart Valve Dis. 1993;2:326-40.

16. Barber JE, Ratliff NB, Cosgrove DM 3rd, Griffin BP, Vesely I. Myxomatous mitral valve chordae. I: mechanical properties. $J$ Heart Valve Dis. 2001;10:320-4.

17. Davies MJ. Pathology of cardiac valves. London: Butterworth; 1980 p. 1-61.

18. Rippe J, Fishbein MC, Carabello B, Angoff G, Sloss L, Collins JJ Jr, et al. Primary myxomatous degeneration of cardiac valves. Clinical, pathological, haemodynamic, and echocardiographic profile. Br Heart J. 1980;44:621-9.

19. Lim KO, Boughner DR, Perkins DG. Ultrastructure and mechanical properties of chordae tendineae from a myxomatous tricuspid valve. Jpn Heart J. 1983;24:539-48.

20. Whittaker P, Boughner DR, Perkins DG, Canham PB. Quantitative structural analysis of collagen in chordae tendineae and its relation to floppy mitral valves and proteoglycan infiltration. Br Heart J. 1987; 57:264-9.

21. Wooley CF, Baker PB, Kolibash AJ, Kilman JW, Sparks EA, Boudoulas $\mathrm{H}$. The floppy, myxomatous mitral valve, mitral valve prolapse, and mitral regurgitation. Prog Cardiovasc Dis. 1991;33:397-433.

\section{Authoritative}

The Journal of Thoracic and Cardiovascular Surgery is the most frequently cited thoracic/cardiovascular surgery journal in the Science Citation Index. An article in JTCVS is sited on average almost twice as often as those in the closest cardiothoracic journal. 